\title{
Current and Future Therapeutics for Patients with Non-small Cell Lung Cancer and Known Activating Mutations in Epidermal Growth Factor Receptor
}

\author{
Moon Fenton, MD, PhD \\ Medical Oncologist and Hematologist, The West Clinic, Memphis, Tennessee, US
}

DOl: http://doi.org/10.17925/OHR.2015.11.02.128

\begin{abstract}
Treatment for advanced non-small cell lung cancer (aNSCLC) is no longer based solely on histologic subtype. Recent discoveries have led to treatments tailored to the molecular drivers associated with each tumor (e.g., epidermal growth factor receptor [EGFR]-activating mutations). In the US, there are now three approved EGFR tyrosine kinase inhibitors (TKIS): gefitinib, erlotinib, and afatinib for first-line therapy in EGFR mutation-positive metastatic NSCLC. These agents have comparable efficacy, however, their tolerability profiles differ. Therefore, multiple factors should be considered before initiation of therapy. NSCLC tumors eventually develop resistance to EGFR TKIS; the most prevalent resistance mechanism is the EGFR T790M mutation, which occurs in 51-68 \% of EGFR TKI-resistant aNSCLC. Two agents, osimertinib (AZD9291) and rociletinib (CO-1686), are currently in late-stage development. They target the T790M mutation and are expected to provide an important option for patients with acquired resistance to EGFR TKIs. Identification of the T790M mutation or other resistance mechanisms will allow for a personalized treatment approach for patients with EGFR TKI-resistant aNSCLC. This review discusses the current and future treatment options for patients with activating mutations in EGFR and the importance of biopsy and molecular testing at disease progression.
\end{abstract}

\section{Keywords}

Epidermal growth factor receptor, tyrosine kinase inhibitors, non-small cell lung cancer, gefitinib, afatinib, erlotinib, AZD9291, osimertinib, rociletinib

Disclosure: Moon Fenton, MD, has consulted for AstraZeneca. There are no publication fees associated with this article. Open Access: This article is published under the Creative Commons Attribution Noncommercial License, which permits any noncommercial use, distribution, adaptation, and reproduction provided the original author(s) and source are given appropriate credit. Received: September 17, 2015 Accepted: October 30, 2015 Citation: Oncology \& Hematology Review, 2015;11(2):128-34 Correspondence: Moon Fenton, MD, PhD, 1588 Union Avenue, Memphis, TN 38104, US. E: mfenton@westclinic.com

Support: The author wishes to thank Marissa Nolan, PhD, of The Lockwood Group, for providing writing and editorial assistance funded by AstraZeneca.

Lung cancer is the most common cancer in the US with an estimated 221,200 new cases in 2015. An estimated 158,040 patients will die of the disease this year. ${ }^{1}$ The overall 5-year survival rate for all stages of lung cancer is $17 \%$, and for advanced disease, $4 \% .{ }^{1}$ Lung cancer will account for approximately $27 \%$ of all cancer deaths in the US in 20151; these statistics underscore the need for effective therapeutic agents in this patient population.

Histologically, the majority (85\%) of lung cancers are classified as non-small cell lung cancers (NSCLCS), ${ }^{2}$ comprising squamous cell carcinoma (25-30 \% of all lung cancers), adenocarcinoma ( 40\%), and large-cell carcinoma (10$15 \%){ }^{3}$ Advances in the past decade now allow for treatment of NSCLC based on molecular subtype versus solely by histologic subtype of the tumor.2,4 Genetic alterations that contribute to the pathogenesis of NSCLC and are reasonable targets for pharmacotherapies have been identified, including epidermal growth factor receptor (EGFR)-activating gene mutations and anaplastic lymphoma kinase $(A L K)$ gene rearrangements. ${ }^{5-8}$ Other emerging targets involving genetic alteration include ROS1 rearrangements, BRAF V600E mutation, mesenchymal epithelial transition factor (MET) amplification, human epidermal growth factor 2 (HER2) mutations, and rearranged during transfection (RET) rearrangements. ${ }^{2,9}$

The prevalence of EGFR mutations (EGFRm) in NSCLC ranges from 7-14 \% in Western populations and 30-50 \% in Asian populations. ${ }^{2,7,10-13}$ Among patients with NSCLC, EGFRm is more commonly seen in women (42\%) versus men (14\%); in never smokers (51\%) versus smokers (10 \% ); and in adenocarcinoma histology (40 \%) versus nonadenocarcinomas (3\%). ${ }^{11}$

EGFRm drive tumor growth and progression by activating cell survival and proliferation signal transduction cascades. ${ }^{14} \mathrm{~A}$ subset of these activating EGFRm are commonly referred to as sensitizing mutations because their presence is predictive of response to EGFR tyrosine kinase inhibitors (TKIS) .5,6 The most common sensitizing EGFR gene mutations are deletions in exon 19 (ex19del; 45-49 \%) and point mutations in exon 21 (L858R; 40 \%). 2,11,15-18 
Similarly, ALK-rearranged patients treated with $A L K$ inhibitors such as crizotinib have demonstrated high overall response rates. ${ }^{19}$ Therefore, guidelines from the National Comprehensive Cancer Network (NCCN), National Cancer Center, American Society of Clinical Oncology, College of American Pathologists, International Association for the Study of Lung Cancer, and Association for Molecular Pathology all recommend routine EGFR and ALK testing and strongly recommend molecular profiling to identify rare actionable alterations that already have effective agents or are being studied in clinical trials for patients with nonsquamous adenocarcinoma NSCLC. 2,4,20

This review examines the clinical evidence supporting three EGFR TKIs currently available for first-line treatment of EGFRm-positive metastatic NSCLC in the US. It also discusses resistance mechanisms acquired by tumors after treatment with EGFR TKIs and how to identify the actionable mutations at disease progression. Lastly, current and future therapies for treatment of EGFR TKI-resistant NSCLC are reviewed.

\section{EGFR Tyrosine Kinase Inhibitors}

The current NCCN guidelines treatment paradigm recommends EGFR inhibitors as a first-line treatment for patients with EGFRm-positive advanced or metastatic NSCLC. ${ }^{2}$ The available TKIs for first-line treatment of metastatic NSCLC are gefitinib (IRESSA ${ }^{\circledR}$; AstraZeneca, Wilmington, DE), erlotinib (Tarceva ${ }^{\circledR}$; OSI Pharmaceuticals, LLC, Farmingdale, NY), and afatinib (GILOTRIF ${ }^{\circledR}$; Boehringer Ingelheim Pharmaceuticals, Inc., Ridgefield, CT) with response rates ranging from 56 to $84 \%$ and a median progressionfree survival (PFS) in the range of 8-14 months. ${ }^{12,13,16,17,21-25}$

\section{Gefitinib}

Gefitinib is a first-in-class EGFR TKI that was initially introduced in 2002 in Japan and other parts of the world. ${ }^{26,27}$ Gefitinib was introduced to the US market in 2003; however, in 2005 its use was restricted based on lack of survival benefit in an unselected patient population in a phase III trial. ${ }^{26}$ Following the discovery of EGFRm, ,5,6 gefitinib became available in the EU in 2009. ${ }^{27}$ More recently, gefitinib was reintroduced in the US for the firstline treatment of EGFRm-positive metastatic NSCLC, based on the results of two clinical trials. ${ }^{28}$ IRESSA ${ }^{\circledR}$ Follow-Up Measure (IFUM) was an openlabel, single-arm, phase IV, bridging study of first-line gefitinib conducted in Caucasian patients with EGFRm-positive advanced NSCLC (aNSCLC; $\mathrm{n}=106$ ). Gefitinib-treated patients experienced an objective response rate (ORR) of $70 \%$ (95\% confidence interval [CI], 61-78), median PFS of 9.7 months, and median overall survival (OS) of 19 months. ${ }^{12}$ Supporting these results was a subset analysis of the Iressa Pan-Asia Study (IPASS). The IPASS trial was a phase III, randomized, open-label, multicenter, parallelgroup study in an Asian population that compared first-line gefitinib with carboplatin + paclitaxel chemotherapy in a subset of patients with EGFRm-positive aNSCLC $(n=186) .{ }^{17,28}$ For patients with EGFRm-positive tumors the median PFS (as assessed by blinded independent central review) was 10.9 months for gefitinib compared with 7.4 months for chemotherapy (hazard ratio [HR] 0.54; $95 \% \mathrm{Cl} 0.38-0.79$ ). ${ }^{28}$ Although median OS did not differ between treatment groups (gefitinib, 21.6 months versus chemotherapy, 21.9 months; HR 1.0; $95 \%$ Cl 0.76-1.33), ${ }^{21}$ the ORR was greater for gefitinib-treated patients (67\%; $95 \%$ Cl 56-77\%) compared with patients treated with chemotherapy (41\%; $95 \% \mathrm{Cl} 31-$ $51 \%) .{ }^{28}$ The ORR and PFS in this Asian patient population were similar to those observed in the IFUM Caucasian population ${ }^{17,12}$ and confirm the consistent efficacy of gefitinib in patients of different ethnicities with EGFRm-positive aNSCLC.

\section{Erlotinib}

Erlotinib was approved in the US in 2004 for treatment of locally advanced or metastatic NSCLC after failure of at least one prior chemotherapy regimen.29 It was subsequently approved in 2010 as maintenance treatment for patients without disease progression after four cycles of platinum-based, first-line chemotherapy. ${ }^{29}$ After the discovery of EGFRm, erlotinib received approval in 2013 as first-line treatment in patients with EGFRm-positive metastatic NSCLC, based on the results of an open-label, randomized, phase III study (the European Tarceva versus Chemotherapy [EURTAC] trial). ${ }^{13}$ Caucasian patients with EGFRm-positive aNSCLC treated with erlotinib experienced significant improvement in median PFS (10.4 months) compared with those who received a standard-of-care platinumbased doublet chemotherapy (5.2 months; HR 0.34; 95 \% Cl 0.23-0.49; $\mathrm{p}<0.0001) .{ }^{29}$ Whereas there was no difference in median OS between erlotinib-treated and chemotherapy-treated patients (22.9 months versus 19.5 months, respectively; $95 \% \mathrm{Cl} 0.64-1.35 ; \mathrm{p}=0.93)$ the ORR was higher for erlotinib versus chemotherapy (65 \%; $95 \%$ Cl 54.1-75.1 \% versus $16 \%$; $95 \% \mathrm{Cl}$ 9.0-25.3\%, respectively). ${ }^{29}$ Although not included in the US label, the OPTIMAL (CTONG-0802) trial was an open-label, randomized, phase III trial of first-line erlotinib versus chemotherapy in Asian patients with EGFRmpositive aNSCLC. ${ }^{23}$ The median PFS was 13.1 months (95 \% Cl 10.58-16.53) for erlotinib-treated patients compared with 4.6 months $(95 \% \mathrm{Cl} 4.21-$ 5.42) for those treated with chemotherapy (HR 0.16; $95 \% \mathrm{Cl} 0.10-0.26$; $\mathrm{p}<0.0001) .{ }^{23}$ Similar to gefitinib, the erlotinib trials demonstrated efficacy in both Asian and Caucasian patients with EGFRm-positive aNSCLC.

\section{Afatinib}

Afatinib was approved in the US in 2013 as first-line treatment of EGFRmpositive metastatic NSCLC, based on the results of the LUX-Lung 3 trial. 16,30 Patients with EGFRm-positive aNSCLC who were treated with afatinib experienced PFS of 11.1 months compared with 6.9 months in patients treated with pemetrexed/cisplatin (HR 0.58; $95 \% \mathrm{Cl} 0.43-0.78 ; \mathrm{p}<0.001$ ), with an ORR of $50.4 \%$ versus $19.1 \%$, respectively. ${ }^{16,30}$

Similar to the results seen with other EGFR TKIs, data from both the LUX-Lung 3 and LUX-Lung 6 (a second open-label, randomized, phase III trial) demonstrated no difference in OS with afatinib compared with chemotherapy (LUX-Lung 3: HR 0.88; $95 \% \mathrm{Cl}$ 0.66-1.17; $p=0.39$; LUX-Lung 6: HR 0.93; 95 \% Cl 0.72-1.22; $\mathrm{p}=0.61) .{ }^{31}$ However, a preplanned analysis of these two trials revealed a significant improvement in OS with afatinib compared with chemotherapy for patients with an EGFR ex19del mutation (LUX-Lung 3: HR 0.54; 95 \% Cl 0.36-0.79, p=0.0015; LUX-Lung 6: HR 0.64; $95 \% \mathrm{Cl} 0.44-0.94 ; p=0.023$ ), but not for patients with the L858R mutation (LUX-Lung 3: HR 1.3; 95 \% Cl 0.80-2.11; $p=0.29$; LUX-Lung 6: HR 1.22; $95 \% \mathrm{Cl} 0.81-1.83 ; \mathrm{p}=0.34) .{ }^{31}$ The reason for such a difference by EGFRm subtype is not fully understood. However, other studies, including a recent meta-analysis, support improved outcomes in patients treated with gefitinib, erlotinib, or afatinib who harbor an EGFR ex19del mutation compared with L858R mutation-positive tumors. ${ }^{32-34}$ Data from other EGFR TKI studies support these observations. In the EURTAC trial, patients in the ex19del subgroup treated with erlotinib had significant improvements in median PFS compared with chemotherapy (HR 0.30; 95 \% Cl 0.18-0.50; $\mathrm{p}<0.0001$ ) but improvement in PFS for patients with L858R mutations was 


\section{Table 1: Selected Adverse Events (>10 \% Incidence*) with EGFR Tyrosine Kinase Inhibitor Treatment in Advanced Non-small Cell Lung Cancer ${ }^{28-30}$}

\begin{tabular}{|c|c|c|c|c|c|c|}
\hline \multirow[t]{2}{*}{ Adverse Events } & \multicolumn{2}{|c|}{$\begin{array}{l}\text { Gefitinib } \\
(n=1,126)^{+}\end{array}$} & \multicolumn{2}{|c|}{$\begin{array}{l}\text { Erlotinib } \\
(n=84)\end{array}$} & \multicolumn{2}{|c|}{$\begin{array}{l}\text { Afatinib } \\
(n=229)\end{array}$} \\
\hline & $\begin{array}{l}\text { All AES, } \\
\%\end{array}$ & $\begin{array}{l}\text { CTC } \\
\text { Grade } \\
3,4 \text {, or } \\
5, \%\end{array}$ & $\begin{array}{l}\text { All AES } \\
\%\end{array}$ & $\begin{array}{l}\text { CTC } \\
\text { Grade } \\
3,4, \text { or } \\
5, \%\end{array}$ & $\begin{array}{l}\text { All AES } \\
\%\end{array}$ & $\begin{array}{l}\text { CTC } \\
\text { Grade } \\
3,4 \text {, or } \\
5, \%\end{array}$ \\
\hline Rash or acne & \multirow{3}{*}{$47^{\ddagger}$} & \multirow{3}{*}{$2^{\ddagger}$} & $85^{\S}$ & $14^{\S}$ & $90 \|$ & $16 \|$ \\
\hline Dry skin & & & 21 & 5 & 31 & 0 \\
\hline Pruritus & & & 16 & 0 & 21 & 0 \\
\hline Diarrhea & 29 & 3 & 62 & 5 & 96 & 15 \\
\hline $\begin{array}{l}\text { Stomatitis/ } \\
\text { mucositis }\end{array}$ & 7 & 0.3 & NR & NR & 71 & 9 \\
\hline $\begin{array}{l}\text { Paronychia/nail } \\
\text { disorders" }\end{array}$ & 5 & 0.01 & 14 & 0 & 58 & 11 \\
\hline Conjunctivitis & 6 & 0 & 18 & 0 & 11 & 0 \\
\hline
\end{tabular}

* Selected adverse events (AES) displayed occurred in $>10 \%$ patients and had increased $>5 \%$ from incidence in respective chemotherapy control group (not displayed); based on prescribing information; ' Data include all patients regardless of epidermal growth factor receptor mutation status in a 2nd/3rd-line trial: ${ }^{26}$ ₹Rates reported include all skin reactions: acne, acne pustular, dermatitis, dermatitis acneiform, dermatitis exfoliative drug eruption, dry skin, erythema, exfoliative rash, folliculitis, pruritus, pruritus generalized, rash, rash erythematous, rash generalized, rash macular, rash macula-papular, rash papular, rash pruritic, rash pustular, rash vesicular, skin exfoliation, skin irritation, skin toxicity, xeroderma: s/ncludes rash, acne, folliculitis, erythema, dermatitis acneiform, dermatitis, palmar-plantar erythrodysaesthesia syndrome, exfoliative rash, rash erythematous, rash pruritic, skin toxicity, eczema, rash follicular, skin ulcer, IIncludes group of rash preferred terms, acne, acne pustular, dermatitis acneiform; "Includes ingrowing nail, nail bed infection, nail bed inflammation, nail bed tenderness, nail disorder, nail dystrophy, nail infection, onychalgia, onychoclasis, onycholysis, onychomadesis, paronychia. aNSCLC = advanced non-small cell lung cancer; $C T C=$ common toxicity criteria; $N R=$ not reported. Data sourced from IRESSA (gefitinib), ${ }^{28}$ TARCEVA (erlotinib), ${ }^{29}$ and GILOTRIF (afatinib) ${ }^{30}$ prescribing information.

not statistically significant (HR 0.55; $95 \% \mathrm{Cl} 0.29-1.02 ; \mathrm{p}=0.0539) .{ }^{13}$ In the IPASS trial, when compared with chemotherapy, gefitinib-treated patients in both mutational subgroups had statistically significant improvements in median PFS (ex19del: HR 0.38; 95 \% Cl 0.26-0.56; L858R: HR 0.55; 95 $\% \mathrm{Cl}$ 0.35-0.87); however, the ex19del subgroup had a slightly greater advantage. ${ }^{21}$ These data suggest different EGFR gene mutations may carry different prognoses. ${ }^{34}$

\section{EGFR Tyrosine Kinase Inhibitor Safety and Tolerability Profiles}

A recent meta-analysis of 28 studies of gefitinib, erlotinib, and afatinib in patients with aNSCLC demonstrated an overall similarity in efficacy among the three agents. ${ }^{35}$ Their safety and tolerability profiles differ, however, and afatinib may be associated with a worse tolerability profile. ${ }^{35}$ Clinical differences between TKIs may be explained by the molecular differences in mechanism of action, structure, and affinity for wild-type (wt) EGFR. ${ }^{36,37}$ Gefitinib and erlotinib are reversible EGFR TKIs that block EGFR activation by binding to the adenosine $5^{\prime}$-triphosphate (ATP) binding site. ${ }^{36,38}$ These agents have increased binding affinity for mutant EGFR compared with WtEGFR. ${ }^{36}$ Afatinib is an irreversible EGFR TKI that covalently binds to mutant EGFR, wtEGFR, and other members of the ErbB family, HER2 and HER4. ${ }^{37}$

Selected adverse events (AES) reported in the prescribing information for each agent are provided in Table 1. Incidence of all grades of skin reactions (including rash) were lower with gefitinib compared with afatinib and erlotinib. Similarly, there were lower rates of all grades of diarrhea with gefitinib compared with the other two agents, while both gefitinib and erlotinib reported lower rates of $\geq$ grade 3 diarrhea compared with afatinib. Afatinib also had higher rates of all grades of stomatitis/mucositis and paronychia compared with erlotinib and gefitinib. The reported discontinuation and dose reduction rates due to AES for these agents markedly differ. ${ }^{28-30}$ Discontinuation rates due to AEs were $14.3 \%$ for patients treated with erlotinib, $14 \%$ for afatinib, and $3 \%$ for gefitinib. Dose interruptions or reductions due to AEs occurred in $37 \%$ of erlotinib-treated and $57 \%$ of afatinib-treated patients. Dose reductions due to AEs were not reported in the gefitinib prescribing information. ${ }^{28-30}$

Evaluation of each agent's safety and tolerability profile is particularly important to treatment selection, as there are no data available to distinguish between the three first-line therapeutic options in metastatic NSCLC. Additionally, patients receiving EGFR TKIs should be monitored to assess treatment response, tolerability to therapy, disease progression, and potential acquired resistance mechanisms. ${ }^{2,39}$

\section{EGFR Tyrosine Kinase Inhibitor Resistance Mechanisms}

Inevitably, acquired resistance to first-line EGFR TKIs occurs in most patients with a median PFS of approximately 12 months (range, 8-14 months) after treatment initiation. ${ }^{12,13,16,17,21-25}$ Clinical progression after EGFR TKI therapy can be broadly categorized into three subtypes, each requiring a different treatment approach. ${ }^{40}$ The first subtype is oligoprogressive disease, defined as progression at new sites or a limited number of areas with regrowth. The second, central nervous system (CNS) sanctuary progressive disease, refers to isolated CNS failure (e.g., brain metastasis) without systemic progression. In this case, progression in the CNS may be the result of poor penetration of the blood-brain barrier by TKIS. ${ }^{40}$ For oligo-progressive disease and CNS sanctuary progressive disease, it is reasonable to institute local therapy with radiation while continuing TKI therapy. ${ }^{2,40}$ The last subtype, systemic progressive disease, is defined as multisite progression with possible new metastatic sites and regrowth in previously responsive areas. ${ }^{40}$ There are multiple approaches to treating systemic progressive disease after EGFR TKI resistance, including continuing on the same TKI, switching to chemotherapy, or adding on a therapy — such as chemotherapy or another targeted agent-to the TKI regimen., ${ }^{2,40}$ It is important to note that these approaches have limited efficacy in progressive disease after EGFR TKI therapy. In the ASPIRATION study, continuation with erlotinib therapy post progression demonstrated a median PFS of only 3.7 months. ${ }^{41}$ Furthermore, the recent IMPRESS trial demonstrated no statistically significant PFS improvement by continuing gefitinib with the chemotherapy after progression on gefitinib. ${ }^{42,43}$ The molecular mechanisms that generate EGFR TKI resistance are many and are distinct from the original tumor, thus they need to be managed differently. ${ }^{44}$ Among them, the most common resistance mechanism is the gatekeeper mutation in the EGFR kinase domain (EGFR T790M), followed by HER2 gene amplification, MET gene amplification, transformation to small-cell carcinoma, and phosphatidylinositide 3-kinase-CA (PIK3A) gene mutation. ${ }^{44,45}$ As more mechanisms of resistance are discovered it becomes increasingly important to not only identify them at disease progression, but also to understand which of these mechanisms can be targeted with currently available agents (see Table 2). 


\section{EGFR T790M}

A substitution of methionine for threonine at the 790 position of exon 20 (T790M) in the EGFR kinase domain is the most common EGFRm, with a reported incidence ranging from 51 to $68 \%$ in patients whose disease has progressed on erlotinib and gefitinib. ${ }^{45-50}$ As afatinib is the newest of the TKIs, there are limited data reporting the incidence of T790M resistance with afatinib disease progression. However, an in vitro model of acquired resistance to first-line afatinib demonstrated that T790M mutations may occur. $^{51}$ Though afatinib appears to have some activity in patients who progressed on other EGFR TKIS (LUX-Lung 1 study), ${ }^{52}$ a more recent study showed no response in patients with a T790M-acquired mutation. ${ }^{53}$ In a phase $\mathrm{Ib}$ trial, the combination of afatinib plus cetuximab in pretreated patients with EGFRm-positive acquired resistance to gefitinib/erlotinib demonstrated a median PFS of 4.7 months (95 \% Cl 4.3-6.4)..$^{54}$ However, larger-scale studies are needed to determine its efficacy and toxicities in comparison with EGFR TKIs that specifically target T790M. Perhaps the combination may be useful in resistant tumors that do not harbor T790M.

The T790M mutation is thought to be resistant to EGFR TKIs through several mechanisms, including steric hindrance from the introduction of a bulkier amino acid (reduced binding of reversible TKIS), increased binding affinity of ATP, and increased phosphorylation levels, leading to reduced potency of TKIS. ${ }^{55-57}$ Multiple novel agents are in clinical development that target the T790M mutation, including osimertinib (AZD9291; AstraZeneca, Wilmington, DE), ASP8273 (Astellas Pharma US, Inc., Northbrook, IL), rociletinib (CO-1686; Clovis Oncology, San Francisco, CA), and HM61713 (Hanmi Pharmaceutical Co, Seoul, Korea). Osimertinib and rociletinib are in phase II clinical development and are discussed in greater detail here.

Osimertinib is an oral, once-daily, irreversible EGFR TKI specifically designed to target both the T790M mutation and mutant EGFR with Iow activity against wtEGFR, the insulin receptor (IR), and the insulinlike growth factor receptor type 1 (IGF-1R). ${ }^{58-60}$ An interim analysis of a phase I/II study demonstrated that patients with T790M mutation-positive aNSCLC $(n=59)$ in the osimertinib $80 \mathrm{mg}$ once-daily arm experienced an ORR of $54 \%$ (95\% Cl 41-67\%) and a duration of response of 12.4 months (95\% Cl 8.3-not calculable) with a median PFS of 13.5 months $(95 \% \mathrm{Cl}$ 8.3-not calculable; $38 \%$ data maturity by central reviewers). ${ }^{61}$ In this same cohort, investigator-assessed data demonstrated an ORR of $66 \%$ (95\% Cl 52-77\%) with the duration of response not calculable $(95 \% \mathrm{Cl}$ 8.2-not calculable) and a median PFS of 10.9 months (95 \% Cl 8.3-not calculable; $40 \%$ data maturity). AEs across all 103 osimertinib-treated patients were mostly mild (grade 1/2) with the most commonly reported being rash (38\%) and diarrhea (36\%). ${ }^{61}$ In this safety population, rates of hyperglycemia were low (4\%), ${ }^{61}$ likely because osimertinib was designed to have minimal activity against IR and IGF-1R.58 Osimertinib is currently under investigation as a first-line therapy verses standard of care in a phase III study (NCT02296125). ${ }^{62}$

Rociletinib (CO-1686) is an oral, twice-daily, irreversible EGFR TKI that targets both the T790M mutation and mutant EGFR with low activity against wtEGFR. Additionally, a metabolite of rociletinib is reported to be an inhibitor of IGF-1R. ${ }^{63,64}$ An updated interim analysis of a phase I/II study was recently presented and showed an ORR of $60 \%$ and a disease control rate of $90 \%$ in T790M mutation-positive aNSCLC patients who received the recommended $500 \mathrm{mg}$ dose $(n=48) .{ }^{65}$ Median PFS was
Table 2: Reported Acquired Mechanisms of EGFR Tyrosine Kinase Inhibitor Treatment Resistance in Advanced Non-small Cell Lung Cancer and Potential Investigative Therapies

\begin{tabular}{|c|c|c|}
\hline $\begin{array}{l}\text { Resistance } \\
\text { Mechanism }\end{array}$ & $\begin{array}{l}\text { Reported } \\
\text { Prevalence Range }\end{array}$ & $\begin{array}{l}\text { Investigational Studies in Pretreated } \\
\text { aNSCLC }\end{array}$ \\
\hline EGFR T790M & $51-68 \% 45-50$ & $\begin{array}{l}\text { - Osimertinib (phase II, NCT02094261; } \\
\text { phase III, NCT02151981) } \\
\text { - Rociletinib (phase II, NCT02147990; } \\
\text { phase III, NCT02322281) }\end{array}$ \\
\hline $\begin{array}{l}\text { HER2 } \\
\text { amplification }\end{array}$ & $13 \%{ }^{45}$ & $\begin{array}{l}\text { - Intermittent, high-dose afatinib } \\
\text { (phase Ib, NCT01647711) } \\
\text { - Neratinib + temsirolimus }{ }^{68}\end{array}$ \\
\hline $\begin{array}{l}\text { MET } \\
\text { amplification }\end{array}$ & $5-11 \% 45,46,69$ & $\begin{array}{l}\text { - Cabozantinib + erlotinib (phase II, } \\
\text { NCT01866410) } \\
\text { • LY2875358 +/- erlotinib (phase II, } \\
\text { NCT01900652) } \\
\text { INC280 + gefitinib (phase Ib/2, } \\
\text { NCT01610336) } \\
\text { - Savolitinib (MET inhibitor; HMPL-504, } \\
\text { volitinib, AZD6094) + osimertinib } \\
\text { (phase Ib, NCT02143466) } \\
\text { - Savolitinib + gefitinib (phase I, } \\
\text { NCT02374645) }\end{array}$ \\
\hline $\begin{array}{l}\text { Transformation } \\
\text { to SCLC }\end{array}$ & $3-14 \% 45,69$ & $\begin{array}{l}\text { - Platinum-etoposide-based } \\
\text { chemotherapy }{ }^{69}\end{array}$ \\
\hline $\begin{array}{l}\text { PI3KCA } \\
\text { mutation }\end{array}$ & $0-5 \%{ }^{7,45,69}$ & $\begin{array}{l}\text { - Buparlisib (BKM120) + erlotinib (phase II, } \\
\text { NCT01487265) } \\
\text { - Buparlisib (BKM120) + gefitinib (phase Ib, } \\
\text { NCT01570296) }\end{array}$ \\
\hline
\end{tabular}

aNSCLC = advanced non-small cell lung cancer; $E G F R=$ epidermal growth factor receptor; HER2 = human epidermal growth factor 2; MET = mesenchymal epithelial transition factor: PI3KCA = phosphatidylinositide $3-$ kinase-CA; $S C L C=$ small-cell lung cancer .

8.0 months (35\% data maturity) in T790M mutation-positive patients treated with $500 \mathrm{~g}$ or $625 \mathrm{mg}$ of rociletinib $(n=270)$. Safety analysis for the 119 patients treated with all formulations of rociletinib $500 \mathrm{mg}$ reported that treatment-related AEs were generally mild. Although there were no reports of rash, diarrhea was reported in $33 \%$ of patients. Hyperglycemia was reported in $35 \%$ of patients, of which $17 \%$ were classified as grade $3 / 4 .{ }^{65}$ The hyperglycemia associated with rociletinib has been linked to the inhibition of the IGF-1R.63,64

In 2014, the US Food and Drug Administration granted breakthrough therapy designation for rociletinib and osimertinib. Both therapies appear to have similar efficacy; however, their tolerability profiles differ, possibly reflecting their different affinities for wtEGFR and other receptors such as IGF-1R. Updated data from the ongoing clinical trials for both therapies are expected. The approval of these agents in the US is eagerly anticipated and will provide a much needed option for patients with T790M mutationpositive aNSCLC.

\section{HER2 Amplification}

HER2 amplification occurs in approximately $13 \%$ of patients with aNSCLC and acquired resistance to EGFR TKIs. ${ }^{45}$ HER2 is a tyrosine kinase within the same family as EGFR; and amplification of the HER2 gene may 
Table 3: Important Biomarkers and Recommended Diagnostic Tests With Potential Treatment Options in Advanced Non-small Cell Lung Cancer

\begin{tabular}{|c|c|c|c|}
\hline Tests & Timing & Methods & Therapy \\
\hline $\begin{array}{l}\text { EGFR sensitizing } \\
\text { mutations (EGFRm) }\end{array}$ & Diagnosis & $\begin{array}{l}\text { RT-PCR, } \\
\text { sequencing, } \\
\text { NGS, ctDNA* }\end{array}$ & $\begin{array}{l}\text { Erlotinib }^{\dagger} \\
\text { Gefitinib }^{\dagger} \\
\text { Afatinib }^{+}\end{array}$ \\
\hline EGFR T790M & $\begin{array}{l}\text { Disease } \\
\text { progression }\end{array}$ & $\begin{array}{l}\text { RT-PCR, } \\
\text { Sequencing, } \\
\text { NGS, ctDNA* }\end{array}$ & $\begin{array}{l}\text { Osimertinib } \ddagger \\
\text { Rociletinib }\end{array}$ \\
\hline$A L K$ rearrangement & Diagnosis & FISH, IHC & $\begin{array}{l}\text { Crizotinibb }^{\dagger} \\
\text { Ceritinib }^{\dagger}\end{array}$ \\
\hline ROS1 rearrangements & Diagnosis & $\mathrm{FISH}, \mathrm{IHC}$ & Crizotinib $^{\dagger}$ \\
\hline$R E T$ rearrangement & Diagnosis & $\mathrm{FISH}$ & Cabozantinib $^{\dagger}$ \\
\hline $\begin{array}{l}\text { HER2 mutation or } \\
\text { amplification }\end{array}$ & $\begin{array}{l}\text { Diagnosis and } \\
\text { disease progression }\end{array}$ & $\mathrm{ISH}, \mathrm{IHC}$ & $\begin{array}{l}\text { Trastuzumab } \\
\text { Afatinib }^{\dagger}\end{array}$ \\
\hline $\begin{array}{l}\text { BRAF V } 600 \mathrm{E} \\
\text { mutation }\end{array}$ & $\begin{array}{l}\text { Diagnosis and } \\
\text { disease progression }\end{array}$ & $\begin{array}{l}\text { RT-PCR, } \\
\text { Sequencing, } \\
\text { NGS, IHC }\end{array}$ & $\begin{array}{l}\text { Vemurafenib }{ }^{\dagger} \\
\text { Dabrafenib }^{\dagger}\end{array}$ \\
\hline MET amplification & $\begin{array}{l}\text { Diagnosis and diseas } \\
\text { progression }\end{array}$ & IHC, ISH & $\begin{array}{l}\text { No recommended } \\
\text { agents }\end{array}$ \\
\hline \multicolumn{4}{|c|}{$\begin{array}{l}\text { *Soon to be available in the US, currently only available in the EU; }{ }^{+P e r} \text { National Comprehensive } \\
\text { Cancer Network guidelines; }{ }^{2} \text { Anticipated US Food and Drug Administration approval in late } \\
2015 \text { based on phase II data: NCTO2094261 and NCT02147990. ALK = anaplastic lymphoma } \\
\text { kinase; ctDNA = circulating tumor DNA; EGFR = epidermal growth factor receptor; EGFRm = } \\
\text { epidermal growth factor receptor mutation; FISH = fluorescence in situ hybridization; HER2 = } \\
\text { human epidermal growth factor 2; IHC = immunohistochemistry; ISH = in situ hybridization; MET= } \\
\text { mesenchymal epithelial transition factor; NGS = next-generation sequencing; } R E T=\text { rearranged } \\
\text { during transfection; RT-PCR = reverse transcription polymerase chain reaction. }\end{array}$} \\
\hline
\end{tabular}

mediate EGFR TKI resistance by stimulating the same downstream cell growth and survival pathways, such as the phosphatidylinositide 3-kinase (PI3K)/mammalian target of rapamycin (mTOR) pathway. ${ }^{66}$

There are a few agents under investigation that target HER2 in pretreated aNSCLC (see Table 2). Dacomitinib, an irreversible pan-HER inhibitor, was investigated in a double-blind, randomized, phase III trial in heavily pretreated patients with aNSCLC and did not demonstrate a significant increase in OS compared with placebo. ${ }^{67}$ Intermittent, high-dose afatinib, ${ }^{44}$ as well as combination therapy with neratinib plus temsirolimus, ${ }^{68}$ show promising results in aNSCLC in phase I trials.

\section{MET Amplification}

The reported prevalence of secondary MET amplification in aNSCLC is between 5-11 \%. ${ }^{45,4,6,69}$ MET activates the PI3K pathway, which bypasses the need for EGFR activation. ${ }^{44}$ Combining an agent that blocks the MET pathway while inhibiting EGFR may prevent the resistance/bypass mechanism from being selected..$^{70}$ This was investigated in a phase $\|$ trial of onartuzumab plus erlotinib in patients with recurrent aNSCLC. The combination showed significant improvement in PFS (HR 0.53; $p=0.04$ ) and OS (HR 0.37; $p=0.002$ ) in MET-positive patients treated with the combination therapy versus erlotinib alone $(n=66)^{71}$; however, a subsequent phase III trial using the same combination showed no OS advantage,,$^{72}$ perhaps due to having not selected EGFRm-positive patients..$^{73}$ Exploratory analyses are now underway for different molecular subgroups. ${ }^{72}$ Other MET inhibitor combinations currently under investigation in EGFR TKI-resistant aNSCLC are listed in Table 2.

\section{Transformation to Small-cell Lung Cancer}

Two studies found that histologic transformation of aNSCLC to small-cell lung cancer (SCLC) occurs in approximately 3-14 \% of patients with EGFR TKI-acquired resistance. ${ }^{45.69} \mathrm{An}$ alternative theory suggests that this may not be transformation, but rather that an SCLC clone is associated with NSCLC and as the adenocarcinoma is treated with TKI therapy, the SCLC is able to grow. ${ }^{74}$ In Sequist et al., four patients who had SCLC were treated with the classic SCLC treatment, platinum-etoposide-based chemotherapy, and a $60 \%$ response rate was observed. ${ }^{69}$

\section{PI3KCA Mutations (PI3Kinase)}

Studies have also found that mutations in the PI3KCA gene range from 0-5 \% of patients with EGFR TKI-acquired resistance. ${ }^{7.45,69}$ The PI3K cell growth and survival pathway is downstream of EGFR and therefore targeting the PI3K pathway could potentially have a synergistic effect when used with an EGFR inhibitor. ${ }^{44}$ Two clinical trials are currently investigating the pan-class I PI3K inhibitor buparlisib (BKM120) in combination with erlotinib (phase II, NCT01487265) or gefitinib (phase Ib, NCT01570296) in EFGR TKI-resistant aNSCLC.

\section{Biopsy and Molecular Testing at Disease Progression}

According to the NCCN, reevaluation with biopsy upon disease progression is reasonable for the identification of patients with actionable mutations or those who may have SCLC histology. ${ }^{2}$ However, a recent NCCN survey indicates that only $\sim 27 \%$ of clinicians generally conduct a biopsy at disease progression. ${ }^{75}$ This low percentage may be explained by perceived barriers associated with biopsy at disease progression (e.g., patient unwillingness, AEs associated with the biopsy procedures, insufficient tissue acquisition). ${ }^{76}$ Additionally, physicians may be less willing to test without having approved targeted therapies available. According to one prospective multicenter study (GFPC study 12-01) that assessed the feasibility and clinical utility of biopsy upon disease progression in aNSCLC, $>90 \%$ of the time patients are willing to undergo biopsy. ${ }^{77}$ Of the $82 \%$ of patients with a biopsy upon progression, $94 \%$ and $74.4 \%$ of tumors can be histologically and molecularly analyzed, respectively.7 Two separate studies reported low (<5\%) biopsy-related AES at progression. 69,77 Based on these findings it is critical that the mechanisms of resistance are identified at the point of disease progression in order to guide subsequent therapeutic choices.

Tissue biopsy at progression requires collaboration among oncologists, interventional radiologists, and/or pulmonologists and pathologists. ${ }^{78}$ The types of testing will vary by institution and practice, but may include commercially available kits (eg, cobas ${ }^{\circledR}$ EGFR Mutation Test, Roche Diagnostics, Indianapolis, IN; and FoundationOne ${ }^{\circledast}$ testing, Foundation Medicine, Inc., Cambridge, MA) or laboratory-developed tests. Other molecular tests include immunohistochemistry $(\mathrm{IHC})$, fluorescence in situ hybridization (FISH), and next-generation sequencing (NGS). ${ }^{79}$ Table 3 lists the types of tests that are routinely ordered for aNSCLC molecular testing and includes tests for both biopsy at initial diagnosis and biopsy at disease progression.

Recent advances in noninvasive approaches such as plasma testing, or "liquid" biopsy, provide an exciting alternative to molecular testing..$^{80}$ Due to the moderate sensitivity of current circulating tumor DNA (ctDNA) assays (range, $46-81 \%$ ), it is important to note that if a test result is negative, 
a tissue biopsy may still be required to rule out a false-negative. ${ }^{12,81-83}$ However, improvements to ctDNA testing are underway that enhance detection, including more sensitive reverse transcription polymerase chain reaction (RT-PCR) and the development of newer methods, such as digital PCR. ${ }^{22,84}$

ctDNA testing is available in Europe as an assessment for EGFRm status and it may be used where no tumor sample is available, or as a means to monitor disease progression. This test is highly predictive of EGFRm tumors. $12,80,81,85$ CtDNA testing can also identify the EGFR T790M resistance mutation. ${ }^{83}$ Albeit preliminary, new developments such as EGFR mutational analysis from urine samples are on the horizon. ${ }^{86,87}$

\section{Conclusions}

Choice of first-line therapy for EGFRm-positive aNSCLC should be based on multiple factors, including efficacy (e.g., EGFRm ex19del, L858R, and rare mutations), tolerability profiles, and costs. Unfortunately, most patients' disease will progress on EGFR TKI therapy, highlighting the need to test for mechanisms of resistance and to develop targeted agents. Multiple mechanisms of resistance have been identified, with the most common being the EGFR T790M mutation. Targeted therapies for EGFR T790M, such as osimertinib and rociletinib, will provide crucial options for these patients. Based on the clinical trial data to date, efficacy seems similar for the two agents. However their tolerability profiles differ with different rates of rash and diarrhea, and high rates of hyperglycemia observed with rociletinib. Therefore, choosing which option to use will depend on the ease of administration, dosing schedule, compliance factors, tolerability profile, and cost.

Before osimertinib and rociletinib, chemotherapy was also an important option when choosing a therapy at the time of progression after firstline EGFR TKI treatment, due to its benefits to response rate and PFS. However, patients who have T790M-positive aNSCLC may potentially be treated with third-generation EGFR TKIS, such as osimertinib or rociletinib. Therefore, biopsy at progression on EGFR TKI is strongly recommended to evaluate the mechanism of resistance and guide the selection of targeted therapies. In addition to traditional biopsy methods, "liquid" biopsy or plasma ctDNA could potentially help identify these resistance mechanisms in some patients. This is an exciting time for personalized treatments for aNSCLC, as more research is dedicated to understanding each of these mechanisms of progression and the novel ways to detect and treat them
1. American Cancer Society, Cancer facts \& figures 2015. Available at: http://www.cancer.org/research/cancerfactsstatistics/ cancerfactsfigures2015/ (accessed July 27, 2015).

2. National Comprehensive Cancer Network, NCCN Clinical practice guidelines in oncology: non-small cell lung cancer, 2015; Version 5.2015

3. American Cancer Society, Non-small cell lung cancer. Available at: http://www.cancer.org/cancer/lungcancer-non-smallcell/ index/ (accessed July 27, 2015).

4. Lindeman $\mathrm{NI}$, Cagle PT, Beasley MB, et al., Molecular testing guideline for selection of lung cancer patients for EGFR and ALK tyrosine kinase inhibitors: guideline from the college of American Pathologists, International Association for the Study of Lung Cancer, and Association for Molecular Pathology, I Thorac Oncol, 2013;8:823-9.

5. Lynch TJ, Bell DW, Sordella R, et al., Activating mutations in the epidermal growth factor receptor underlying responsiveness of non-small-cell lung cancer to gefitinib, $N$ Eng/ I Med 2004:350:2129-39.

6. Paez JG, Janne PA, Lee JC, et al., EGFR mutations in lung cancer correlation with clinical response to gefitinib therapy, Science, 2004;304:1497-1500

7. Sequist LV, Heist RS, Shaw AT, et al., Implementing multiplexed genotyping of non-small-cell lung cancers into routine clinical practice, Ann Oncol, 2011:22:2616-24.

8. Soda M, Choi YL, Enomoto M, et al., Identification of the transforming EML4-ALK fusion gene in non-small-cell lung cancer, Nature, 2007:448:561-6.

9. Shaw AT, Ou SH, Bang YJ, et al., Crizotinib in ROS1-rearranged non-small-cell lung cancer, N Engl J Med, 2014;371:1963-71.

10. Sekine I, Yamamoto N, Nishio K, Saijo N, Emerging ethnic differences in lung cancer therapy, Br J Cancer, 2008;99:1757-62.

11. Shigematsu H, Lin L, Takahashi T, et al., Clinical and biological features associated with epidermal growth factor receptor gene features associated with epidermal growth factor receptor gene

12. Douillard JY, Ostoros G, Cobo M, et al., First-line gefitinib in Caucasian EGFR mutation-positive NSCLC patients: a phase-IV, open-label, single-arm study, Br J Cancer, 2014;110:55-62.

13. Rosell R, Carcereny E, Gervais R, et al., Spanish Lung Cance Group in collaboration with Groupe Français de PneumoCancérologie and Associazione Italiana Oncologia Toracica Erlotinib versus standard chemotherapy as first-line treatment for European patients with advanced EGFR mutation-positive non-small-cell lung cancer (EURTAC): a multicentre, open-label, randomised phase III trial, Lancet Oncol, 2012;13:239-246.

14. Herbst RS, Heymach JV, Lippman SM, Lung cancer, N Engl I Med, 2008:359:1367-80

15. D'Angelo SP, Pietanza MC, Johnson ML, et al., Incidence of EGFR exon 19 deletions and L858R in tumor specimens from men and cigarette smokers with lung adenocarcinomas, J Clin Oncol, 2011:29:2066-2070

16. Sequist LV Yang IC, Yamamoto $N$, et al., Phase III study of afatinib or cisplatin plus pemetrexed in patients with metastatic lung adenocarcinoma with EGFR mutations, I Clin Oncol, 2013;31:3327-34

17. Mok TS, Wu YL, Thongprasert S, et al., Gefitinib or carboplatinpaclitaxel in pulmonary adenocarcinoma, N Eng/ I Med,
2009;361:947-57.

18. Siegelin $M D$, Borczuk $A C$, Epidermal growth factor receptor mutations in lung adenocarcinoma, Lab Invest, 2014;94:129-37.

19. Kwak EL, Bang YJ, Camidge DR, et al., Anaplastic lymphoma kinase inhibition in non-small-cell lung cancer, N Engl J Med, 2010;363:1693-1703.

20. American Society of Clinical Oncology, ASCO endorses CAP/ IASLC/AMP guideline on EGFR and ALK molecular testing for patients with lung cancer, 2014. Available at: http://www asco. org/press-center/asco-endorses-capiaslcamp-guideline-egfrand-alk-molecular-testing-patients-lung-cancer/ (accessed July 27, 2015)

21. Fukuoka $\mathrm{M}, \mathrm{Wu} \mathrm{YL}$, Thongprasert $\mathrm{S}$, et al., Biomarker analyse and final overall survival results from a phase III, randomized, open-label, first-line study of gefitinib versus carboplatin/ paclitaxel in clinically selected patients with advanced non-small-cell lung cancer in Asia (IPASS), J Clin Oncol, 2011:29:2866-74.

22. Han JY, Park K, Kim SW, et al., First-SIGNAL: first-line single-agent iressa versus gemcitabine and cisplatin trial in never-smokers with adenocarcinoma of the lung, J Clin Oncol, 2012;30:1122-28.

23. Zhou $\mathrm{C}$, Wu YL, Chen G, et al., Erlotinib versus chemotherapy as first-line treatment for patients with advanced EGFR mutationpositive non-small-cell lung cancer (OPTIMAL, CTONG-0802): a multicentre, open-label, randomised, phase 3 study, Lancet Oncol, 2011:12:735-42.

24. Mitsudomi T, Morita S, Yatabe Y, et al, Gefitinib versus cisplatin plus docetaxel in patients with non-small-cell lung cancer harbouring mutations of the epidermal growth factor receptor (WJTOG3405): an open label, randomised phase 3 trial, Lancet Oncol, 2010;11:121-28.

25. Maemondo M, Inoue A, Kobayashi K, et al., Gefitinib or chemotherapy for non-small-cell lung cancer with mutated EGFR, N Engl I Med, 2010:362:2380-88.

26. Thatcher N, Chang A, Parikh P, et al., Gefitinib plus best supportive care in previously treated patients with refractory advanced non-small-cell lung cancer: results from a randomised, placebo-controlled, multicentre study (Iressa Survival Evaluation in Lung Cancer), Lancet, 2005;366:1527-37.

27. Pircher A, Ploner F, Popper H, Hilbe W, Rationale of a relaunch of gefitinib in Caucasian non-small cell lung cancer patients, Lung Cancer, 2010:69:265-71.

28. IRESSA (gefitinib) prescribing information, Wilmington, DE: Astrazeneca Pharmaceuticals LP. 2015.

29. TARCEVA (erlotinib) tablets prescribing information, Farmingdale, NY: OSI Pharmaceuticals LLC; Apr 2015

30. GILOTRIF (afatinib) prescribing information, Ridgefield, CT: Boehringer Ingelheim Pharmaceuticals, Inc; Apr 2014

31. Yang JC, Wu YL, Schuler M, et al., Afatinib versus cisplatinbased chemotherapy for EGFR mutation-positive lung adenocarcinoma (LUX-Lung 3 and LUX-Lung 6): analysis of overall survival data from two randomised, phase 3 trials, Lancet Oncol, 2015;16:141-51.

32. Jackman DM, Yeap BY, Sequist LV, et al., Exon 19 deletion mutations of epidermal growth factor receptor are associated with prolonged survival in non-small cell lung cancer patients treated with gefitinib or erlotinib, Clin Cancer Res,
2006:12:3908-14

33. Riely GJ, Pao W, Pham D, et al., Clinical course of patients with non-small cell lung cancer and epidermal growth factor receptor exon 19 and exon 21 mutations treated with gefitinib or erlotinib, Clin Cancer Res, 2006;12:839-44.

34. Lee CK, Wu YL, Ding PN, et al., Impact of specific epidermal growth factor receptor (EGFR) mutations and clinical characteristics on outcomes after treatment with EGFR tyrosine kinase inhibitors versus chemotherapy in EGFR-mutant lung cancer: a meta-analysis, J Clin Oncol, 2015:33:1958-65.

35. Burotto M, Manasanch EE, Wilkerson J, Fojo T, Gefitinib and erlotinib in metastatic non-small cell lung cancer: a metaanalysis of toxicity and efficacy of randomized clinical trials, Oncologist, 2015;20:400-10.

36. Bronte G, Rolfo C, Giovannetti E, et al., Are erlotinib and gefitinib interchangeable, opposite or complementary for non-small cell Jung cancer treatment? Biological, pharmacological and clinical aspects, Crit Rev Oncol Hematol, 2014:89:300-13.

37. Modjtahedi $\mathrm{H}, \mathrm{Cho} B \mathrm{C}$, Michel MC, Solca F, A comprehensive review of the preclinical efficacy profile of the ErbB family blocker afatinib in cancer, Naunyn Schmiedebergs Arch Pharmacol, 2014;387:505-21.

38. Wakeling AE, Guy SP, Woodburn JR, et al., ZD1839 (Iressa): an orally active inhibitor of epidermal growth factor signaling with potential for cancer therapy, Cancer Res, 2002;62:5749-54.

39 Rolfo C, Giovannetti $\mathrm{E}$, Hong DS, et al., Novel therapeutic strategies for patients with NSCLC that do not respond to treatment with EGFR inhibitors, Cancer Treat Rev, 2014;40:990-1004.

40. Gandara DR, Li T, Lara PN, et al., Acquired resistance to targeted therapies against oncogene-driven non-small-cell lung cancer: approach to subtyping progressive disease and clinical implications, Clin Lung Cancer, 2014:15:1-6.

41. Park K, Ahn M, Yu C, et al., ASPIRATION: first-line erlotinib (E) until and beyond RECIST progression (PD) in asian patients (pts) with EGFR mutation-positive (MUT+) NSCLC, Ann Oncol, 2014;25:12230.

42. Mok TSK, Wu Y, Nakagawa K, et al., LBA2_PR gefitinib/ chemotherapy vs chemotherapy in epidermal growth factor receptor (EGFR) mutation-positive non-small-cell lung cancer (NSCLC) after progression on first-line gefitinib: the phase III, randomised IMPRESS study, Ann Oncol, 2014;25.

43. Soria JC, Kim S, Wu Y, et al., Gefitinib/chemotherapy vs chemotherapy in EGFR mutation positive NSCLC resistant to first-line gefitinib: IMPRESS T790M Subgroup Analysis, I Thorac Oncol, 2015;10(Suppl. 2):S207.

44. Sacher AG, Janne PA, Oxnard GR, Management of acquired resistance to epidermal growth factor receptor kinase inhibitors in patients with advanced non-small cell lung cancer, Cancer, 2014;120:2289-98.

45. Yu HA, Arcila ME, Rekhtman $N$, et al., Analysis of tumor specimens at the time of acquired resistance to EGFR-TKI therapy in 155 patients with EGFR-mutant lung cancers, Clin Cancer Res, 2013;19:2240-47.

46. Arcila ME, Oxnard GR, Nafa K, et al., Rebiopsy of lung cancer patients with acquired resistance to EGFR inhibitors and enhanced detection of the T790M mutation using a locked nucleic acid-based assay, Clin Cancer Res, 2011;17:1169-80. 
47. Oxnard GR, Arcila ME, Sima CS, et al., Acquired resistance to EGFR tyrosine kinase inhibitors in EGFR-mutant lung cancer: distinct natural history of patients with tumors harboring the T790M mutation, Clin Cancer Res, 2011:17:1616-22.

48. Sun JM, Ahn MJ, Choi YL, et al., Clinical implications of T790M mutation in patients with acquired resistance to EGFR tyrosine kinase inhibitors, Lung Cancer, 2013;82:294-98.

49. Li W, Ren S, Li J, et al., T790M mutation is associated with better efficacy of treatment beyond progression with EGFR-TKI in advanced NSCLC patients, Lung Cancer, 2014;84:295-300.

50. Kuiper UL, Heideman DA, Thunnissen E, et al., Incidence of T790M mutation in (sequential) rebiopsies in EGFR-mutated NSCLC-patients, Lung Cancer 2014:85:19-24.

51. Kim Y, Ko J, Cui Z, et al., The EGFR T790M mutation in acquired resistance to an irreversible second-generation EGFR inhibitor, Mol Cancer Ther, 2012;11:784-91.

52. Miller VA, Hirsh V, Cadranel J, et al., Afatinib versus placebo for patients with advanced, metastatic non-small-cell lung cance after failure of erlotinib, gefitinib, or both, and one or two lines of chemotherapy (LUX-Lung 1): a phase $2 \mathrm{~b} / 3$ randomised trial , Lancet Oncol, 2012:13:528-38.

53. Landi L, Tiseo M, Chiari R, et al. Activity of the EGFR-HER2 dual inhibitor afatinib in EGFR-mutant lung cancer patients with acquired resistance to reversible EGFR tyrosine kinase inhibitors, Clin Lung Cancer, 2014;15:411-17.

54. Janjigian YY, Smit EF, Groen HJ, et al., Dual inhibition of EGFR with afatinib and cetuximab in kinase inhibitor-resistant EGFRmutant lung cancer with and without T790M mutations, Cancer Discov, 2014;4:1036-45.

55. Kobayashi S, Boggon TJ, Dayaram T, et al., EGFR mutation and resistance of non-small-cell lung cancer to gefitinib, N Eng/ Med, 2005;352:786-92.

56. Yun $\mathrm{CH}$, Mengwasser $\mathrm{KE}$, Toms $\mathrm{AV}$, et al., The T790M mutation in EGFR kinase causes drug resistance by increasing the affinity for ATP, Proc Natl Acad Sci U S A, 2008;105:2070-5.

57. Cortot $\mathrm{AB}$, Janne $\mathrm{PA}$, Molecular mechanisms of resistance in epidermal growth factor receptor-mutant lung in epiderma groving

58. Cross DA, Ashton SE, Ghiorghiu S, et al., AZD9291, an irreversible EGFR TKI, overcomes T790M-mediated resistance to EGFR inhibitors in lung cancer, Cancer Discov, 2014;4:1046-61.

59. Finlay MR, Anderton M, Ashton S, et al., Discovery of a potent and selective EGFR inhibitor (AZD9291) of both sensitizing and T790M resistance mutations that spares the wild type form of the receptor, I Med Chem, 2014:57:8249-67.

60. Janne PA, Yang JC, Kim DW, et al., AZD9291 in EGFR inhibitor-resistant non-small-cell lung cancer, N Eng/ J Med, 2015:372:1689-99.

61. Janne PA, Ahn M, Kim D, et al., LBA3 - A phase I study of AZD9291 in patients with EGFR-TKI-resistant advanced NSCLC - updated progression free survival and duration of response data, Ann Oncol, 2015;26:i60.

62. Ramalingam SS, Rukazenkov Y, Thomas K, Soria J-C, A randomized, phase III study (FLAURA) of AZD9291, a novel EGFR-TKI, versus gefitinib or erlotinib in treatment-naive patients with advanced non-small cell lung cancer and an EGFR-TKI-sensitizing mutation, J Clin Oncol, 2015;33(Suppl): abstr. TPS8102.

63. Sequist LV, Soria JC, Goldman JW, et al., Rociletinib in EGFR-mutated non-small-cell lung cancer, N Eng/ J Med 2015;372:1700-09.

64. Soria J-C, Sequist LV, Goldman J, et al., Interim phase 2 results of study CO-1686-008: A phase 1/2 study of the irreversible, mutant selective, EGFR inhibitor rociletinib (CO-1686) in patients with advanced non small cell lung cancer, Eur J Cancer, 2014;50:199.

65. Sequist IV, Goldman JW, Wakelee HA, et al. Efficacy of rociletinib (CO-1686) in plasma-genotyped T790M-positive non-small cell lung cancer (NSCLC) patients (pts). Paper presented at ASCO Annual Meeting; May 29-June 2, 2015; Chicago, IL., I Clin Oncol 2015;33(Suppl. 15):8001.

66. Takezawa K, Pirazzoli V, Arcila ME, et al., HER2 amplification: a potential mechanism of acquired resistance to EGFR inhibition in EGFR-mutant lung cancers that lack the second-site EGFRT790M mutation, Cancer Discov, 2012:2:922-33.

67. Ellis PM, Shepherd FA, Millward M, et al., Dacomitinib compared with placebo in pretreated patients with advanced or metastatic non-small-cell lung cancer (NCIC CTG BR.26): a double-blind randomised, phase 3 trial, Lancet Oncol, 2014;15:1379-88

68. Gandhi L, Bahleda R, Tolaney SM, et al., Phase I study of neratinib in combination with temsirolimus in patients with human epidermal growth factor receptor 2-dependent and other solid tumors, I Clin Oncol, 2014:32:68-75.

69. Sequist LV, Waltman BA, Dias-Santagata D, et al., Genotypic and histological evolution of lung cancers acquiring resistance to EGFR inhibitors, Sci Trans/ Med, 2011;3:75ra26.

70. Ou SH, Second-generation irreversible epidermal growth factor receptor (EGFR) tyrosine kinase inhibitors (TKIs): a better mousetrap? A review of the clinical evidence, Crit Rev Oncol Hematol, 2012;83:407-21.

71. Spigel DR, Ervin TJ, Ramlau RA, et al., Randomized phase ॥ trial of onartuzumab in combination with erlotinib in patients with advanced non-small-cell lung cancer, $/$ Clin Oncol. 2013:31:4105-14.

72. Spigel DR, Edelman MJ, K OB, et al., Onartuzumab plus erlotinib versus erlotinib in previously treated stage IIIb or IV NSCLC: Results from the pivotal phase III randomized, multicenter placebo-controlled METLung (OAM4971g) global trial, J Clin Oncol, 2014:32:8000.

73. Rolfo C, Van Der Steen $N$, Pauwels P, Cappuzzo F, Onartuzumab in lung cancer: the fall of Icarus? Exp Rev Anticancer Ther 2015:15:487-89.

74. Norkowski E, Ghigna M-R, Lacroix L, et al., Small-cell carcinoma in the setting of pulmonary adenocarcinoma: new insights in the era of molecular pathology, I Thorac Oncol, 2013;8:1265-71.

75. Ulrich SL, NCCN Trends ${ }^{\mathrm{TM}}$ Highlights: targeted therapy in nonsmall cell lung cancer. 2013. National Comprehensive
Network website. Available at: http://www.nccn.org/about/ news/ebulletin/ebulletindetail.aspx?ebulletinid=449/ (accessed July 27, 2015).

76. Korpanty G, Leighl NB, Challenges in NSCLC molecular testing Oncologyex.com. 2012;11:8-10. Available at: www.oncologyex. com/pdf/vol11_no4/comment_nsclc-molecular-testing.pd (accessed July 27, 2015).

77. Chouaid C, Dujon C, Do P, et al., Feasibility and clinical impact of re-biopsy in advanced non small-cell lung cancer: a prospective multicenter study in a real-world setting (GFPC study 12-01), Lung Cancer, 2014;86:170-73.

78. Ellis PM, The importance of multidisciplinary team management of patients with non-small-cell lung cancer, Curr Oncol, 2012;19:S7-15.

79. Carrizosa DR, Mileham KF, Haggstrom DE, et al., New targets and new mechanisms in lung cancer, Oncology (Williston Park), 2013;27:396-404

80. Ilie M, Hofman V, Long E, et al., Current challenges for detection of circulating tumor cells and cell-free circulating nucleic acids, and their characterization in non-small cell lung carcinoma patients. What is the best blood substrate for personalized medicine? Ann Trans/ Med, 2014;2:107.

81. Reck M, Hagiwara K, Han B, et al., Investigating the utility of circulating-free tumour-derived DNA (ctDNA) in plasma for the detection of epidermal growth factor receptor (EGFR) mutation status in European and Japanese patients (pts) with advanced non-small-cell lung cancer (aNSCLC): ASSESS study, Ann Oncol, 2015:1-8. Abstract presented at European Lung Cancer Conference, April 17, 2015: Geneva, Switzerland.

82. Thress K, EGFR mutation detection in CtDNA from NSCLC patient plasma: A cross-platform comparison of technologies to support the clinical development of AZD9291, Clin Oncol, 2014;32:8092.

83. Oxnard GR, Paweletz CP, Kuang Y, et al., Noninvasive detection of response and resistance in EGFR-mutant lung cancer using quantitative next-generation genotyping of cell-free plasm DNA, Clin Cancer Res, 2014:20:1698-1705.

84. Zhu G, Ye X, Dong Z, et al., Highly sensitive droplet digital pcr method for detection of EGFR-activating mutations in plasma cell-free DNA from patients with advanced non-small cell lung cancer, J Mol Diagn, 2015;17:265-72

85. Rosell R, Moran T, Queralt C, et al., Screening for epidermal growth factor receptor mutations in lung cancer, $N$ Engl I Med, 2009;361:958-67.

86. Husain H, Kosco K, Guerrero S, et al., Detection of EGFR T790M mutation in urinary circulating tumor DNA from metastatic non-small cell lung cancer patients, Ann Oncol, 2015;26:10-4 Abstract presented at European Lung Cancer Conference 2015 April 17, 2015: Geneva, Switzerland

87. Husain $\mathrm{H}$, Kosco K, Vibat CT, et al., Kinetic monitoring of EGFR T790M in urinary circulating tumor DNA to predict radiographic progression and response in patients with metastatic lung adenocarcinoma, J Clin Oncol, 2015;33:8081. 